\title{
A Japanese multi-institutional randomized controlled trial (ND-Trial)
}

\author{
Stylianos Tzedakis ${ }^{1,2}$, David Fuks ${ }^{1,2}$ \\ ${ }^{1}$ Department of Digestive, Pancreatic, Hepato-biliary and Endocrine Surgery, Cochin Hospital, APHP, Paris, France; ${ }^{2}$ University of Paris, Paris, \\ France \\ Correspondence to: Stylianos Tzedakis, MD. Department of Digestive, Pancreatic, Hepato-biliary and Endocrine Surgery, Cochin Hospital, APHP, \\ University of Paris, 27, rue du Faubourg Saint Jacques, 75014, Paris, France. Email: stylianos.tzedakis@aphp.fr. \\ Comment on: Arita J, Sakamaki K, Saiura A, et al. Drain Placement After Uncomplicated Hepatic Resection Increases Severe Postoperative \\ Complication Rate: A Japanese Multi-institutional Randomized Controlled Trial (ND-trial). Ann Surg 2021;273:224-31.
}

Submitted Feb 01, 2021. Accepted for publication Feb 25, 2021.

doi: $10.21037 / \mathrm{hbsn}-21-57$

View this article at: http://dx.doi.org/10.21037/hbsn-21-57

We read with great interest the recently (Annals of Surgery, Feb, 2021) published article by Arita and collaborators (1) about the clinical impact of a no-drain policy in liver resections. The aforementioned study (ND-trial) is the first multi-institutional randomized controlled trial (RCT) assessing the impact of a drain placement after liver resection on the severe postoperative complication rate.

The use of drains in liver surgery has been established since decades. It is based on the assumption that it will permit monitoring of bleeding or biliary leak as well as mitigating the consequences of such an event. However, advances in the perioperative management of liver resection have led to significantly low bleeding complications $(<1 \%)(2)$. On the other hand, authors using routine drainage recommend early drain removal (before postoperative day 3) in order to reduce the incidence of retrograde bacterial infections despite the fact that most biliary leakages appear on or after the $5^{\text {th }}-7^{\text {th }}$ postoperative day $(3,4)$. The role of drain insertion is thus under ongoing debate.

Previous performed RCTs, most of which already date more than 10 years (5-9), did not support routine drainage following uncomplicated liver resection. However, the conclusions from these studies should be attenuated due to the limited sample size, the low methodological quality and the high heterogeneity in the definition of severe complications. Furthermore, most of these studies were conducted before introduction of the widely accepted Clavien-Dindo classification $(10,11)$.

Based on the results of the present RCT study, the authors suggest that drains should not be placed after hepatic resections in patients who do not exhibit a high risk of postoperative bile leakage or bleeding. Indeed, their results underlined that severe complications (C-D score $\geq 3$ ) as well as bile leakage were significantly lower in the nodrain group, while wound-related complications were comparable in the two groups. Interestingly, subgroup analysis did not identify any high-risk group for which drain placement could prove beneficial.

Despite the high quality of this study, we would like to raise several comments. First, the authors proceeded to patient randomization once liver resection had been completed. Thirty-seven patients considered to be of high risk for bile leakage because of a rough and complex liver transection surface were thus excluded although initially enrolled in the study. Unfortunately, selection of lowrisk patients could introduce major selection bias and results should be interpreted with caution. Moreover, it would have been important to state the criteria on which patients were classified as high or low risk for bile leakage. Indeed, only a small number of patients presented risk factors of bile leakage such as increased BMI, blood loss, hypoalbuminemia, increased indocyanine green clearance rate at $15 \mathrm{~min}$, long operative time or repeated liver resections, while other common risk factors such as blood transfusion were not taken into account (12).

Previous studies have shown that major or central liver resections and non-anatomical resections are more frequently associated with biliary leakage (from $12 \%$ to 
$30 \%$ ) when compared with minor resections (from $4.5 \%$ to $8 \%)(2,13-15)$. Since laparoscopic liver resections seem to have an acceptably low rate of biliary leakage $(2.8-6.2 \%)$, no series suggested any specific benefit on this specific complication (14). In the present study, laparoscopic and open surgery approaches were comparable between the two groups but we should keep in mind that minor hepatectomies represented the majority of liver resections $(87 \%$ and $85 \%$ in the drain and no-drain group, respectively). This low percentage of major 'high-risk' hepatectomies is also revealed by the relative low bile leak rate of $8 \%$ in the drain group. Relative patient selection was finally reflected by a low rate of severe complications $(5 \%)$, which is lower than the one reported in the literature $(8-13 \%)(5,6)$. Last but not least, several other exclusion criteria such as the second step of a 2-stage hepatectomy or "other conditions considered to be inappropriate for inclusion in the study" could have been clarified in the Discussion section.

The authors initially chose a non-inferiority setting for outcome analysis, which was secondarily switched to a superiority analysis. Per protocol (PP) analysis is generally accepted for non-inferiority trials but an intent-to-treat population (ITT) analysis could have been a reasonable choice, given past literature on no-drain policies, as it tends to avoid the over-optimistic estimates of efficacy that result from PP analysis.

In conclusion, this study is the first RCT study to enroll a large number of patients based on a statistical design in order to assess the impact of a no-drain policy on the severe postoperative complication rate. As is so often the case, robust conclusions that favor one particular treatment cannot be drawn for all types of liver resection. However, a no-drain policy for patients having a low risk of postoperative bile leak or bleeding appears to be superior in terms of postoperative severe complication rates.

\section{Acknowledgments}

Funding: None.

\section{Footnote}

Provenance and Peer Review: This article was commissioned by the editorial office of Hepatobiliary Surgery and Nutrition. The article did not undergo external peer review.

Conflicts of Interest: Both authors have completed the
ICMJE uniform disclosure form (available at https://hbsn. amegroups.com/article/view/10.21037/hbsn-21-57/coif). The authors have no conflicts of interest to declare.

Ethical Statement: The authors are accountable for all aspects of the work in ensuring that questions related to the accuracy or integrity of any part of the work are appropriately investigated and resolved.

Open Access Statement: This is an Open Access article distributed in accordance with the Creative Commons Attribution-NonCommercial-NoDerivs 4.0 International License (CC BY-NC-ND 4.0), which permits the noncommercial replication and distribution of the article with the strict proviso that no changes or edits are made and the original work is properly cited (including links to both the formal publication through the relevant DOI and the license). See: https://creativecommons.org/licenses/by-nc-nd/4.0/.

\section{References}

1. Arita J, Sakamaki K, Saiura A, et al. Drain Placement After Uncomplicated Hepatic Resection Increases Severe Postoperative Complication Rate: A Japanese Multiinstitutional Randomized Controlled Trial (ND-trial). Ann Surg 2021;273:224-31.

2. Nguyen KT, Gamblin TC, Geller DA. World review of laparoscopic liver resection-2,804 patients. Ann Surg 2009;250:831-41.

3. Torzilli G, Olivari N, Del Fabbro D, et al. Bilirubin level fluctuation in drain discharge after hepatectomies justifies long-term drain maintenance. Hepatogastroenterology 2005;52:1206-10.

4. Ichida A, Kono Y, Sato M, et al. Timing for removing prophylactic drains after liver resection: an evaluation of drain removal on the third and first postoperative days. Ann Transl Med 2020;8:454.

5. Belghiti J, Kabbej M, Sauvanet A, et al. Drainage after elective hepatic resection. A randomized trial. Ann Surg 1993;218:748-53.

6. Fong $\mathrm{Y}$, Brennan MF, Brown K, et al. Drainage is unnecessary after elective liver resection. Am J Surg 1996;171:158-62.

7. Liu CL, Fan ST, Lo CM, et al. Abdominal drainage after hepatic resection is contraindicated in patients with chronic liver diseases. Ann Surg 2004;239:194-201.

8. Fuster J, Llovet JM, Garcia-Valdecasas JC, et al. Abdominal drainage after liver resection for hepatocellular 
carcinoma in cirrhotic patients: a randomized controlled study. Hepatogastroenterology 2004;51:536-40.

9. Sun HC, Qin LX, Lu L, et al. Randomized clinical trial of the effects of abdominal drainage after elective hepatectomy using the crushing clamp method. Br J Surg 2006;93:422-6.

10. Gavriilidis P, Hidalgo E, de'Angelis N, et al. Re-appraisal of prophylactic drainage in uncomplicated liver resections: a systematic review and meta-analysis. HPB (Oxford) 2017;19:16-20.

11. Dindo D, Demartines N, Clavien PA. Classification of surgical complications: a new proposal with evaluation in a cohort of 6336 patients and results of a survey. Ann Surg 2004;240:205-13.

Cite this article as: Tzedakis S, Fuks D. A Japanese multiinstitutional randomized controlled trial (ND-Trial). HepatoBiliary Surg Nutr 2021;10(2):226-228. doi: 10.21037/ hbsn-21-57
12. Cauchy F, Fuks D, Nomi T, et al. Incidence, risk factors and consequences of bile leakage following laparoscopic major hepatectomy. Surg Endosc 2016;30:3709-19.

13. Kajiwara T, Midorikawa Y, Yamazaki S, et al. Clinical score to predict the risk of bile leakage after liver resection. BMC Surg 2016;16:30.

14. Smith AA, Monlezun DJ, Martinie J, et al. Bile Leak Reduction with Laparoscopic Versus Open Liver Resection: A Multi-institutional Propensity ScoreAdjusted Multivariable Regression Analysis. World J Surg 2020;44:1578-85.

15. Martin AN, Narayanan S, Turrentine FE, et al. Clinical Factors and Postoperative Impact of Bile Leak After Liver Resection. J Gastrointest Surg 2018;22:661-7. 